\title{
Improving health care transition and longitudinal care for adolescents and young adults with hydrocephalus: report from the Hydrocephalus Association Transition Summit
}

\author{
Michael A. Williams, MD, ${ }^{1}$ Tessa van der Willigen, MA, MPhil, ${ }^{2}$ Patience H. White, MD, MA, ${ }^{3}$ \\ Cathy C. Cartwright, MSN, RN, PCNS, ${ }^{4}$ David L. Wood, MD, MPH, ${ }^{5}$ and \\ Mark G. Hamilton, MDCM, FRCSC ${ }^{6}$ \\ 1Departments of Neurology and Neurological Surgery, University of Washington School of Medicine, Seattle, Washington; \\ ${ }^{2}$ Hydrocephalus Association, Bethesda, Maryland; ${ }^{3}$ The National Alliance to Advance Adolescent Health, Washington, DC; \\ ${ }^{4}$ Department of Neurosurgery, Children's Mercy Hospital, Kansas City, Missouri; ${ }^{5}$ Department of Pediatrics, Quillen College of \\ Medicine, East Tennessee State University, Johnson City, Tennessee; and ${ }^{6}$ Department of Neurosurgery, University of Calgary \\ School of Medicine, Calgary, Alberta, Canada
}

\begin{abstract}
The health care needs of children with hydrocephalus continue beyond childhood and adolescence; however, pediatric hospitals and pediatric neurosurgeons are often unable to provide them care after they become adults. Each year in the US, an estimated 5000-6000 adolescents and young adults (collectively, youth) with hydrocephalus must move to the adult health care system, a process known as health care transition (HCT), for which many are not prepared. Many discover that they cannot find neurosurgeons to care for them. A significant gap in health care services exists for young adults with hydrocephalus. To address these issues, the Hydrocephalus Association convened a Transition Summit in Seattle, Washington, February 17-18, 2017.

The Hydrocephalus Association surveyed youth and families in focus groups to identify common concerns with HCT that were used to identify topics for the summit. Seven plenary sessions consisted of formal presentations. Four breakout groups identified key priorities and recommended actions regarding HCT models and practices, to prepare and engage patients, educate health care professionals, and address payment issues. The breakout group results were discussed by all participants to generate consensus recommendations.

Barriers to effective HCT included difficulty finding adult neurosurgeons to accept young adults with hydrocephalus into their practices; unfamiliarity of neurologists, primary care providers, and other health care professionals with the principles of care for patients with hydrocephalus; insufficient infrastructure and processes to provide effective HCT for youth, and longitudinal care for adults with hydrocephalus; and inadequate compensation for health care services.

Best practices were identified, including the National Center for Health Care Transition Improvement's "Six Core Elements of Health Care Transition 2.0"; development of hydrocephalus-specific transition programs or incorporation of hydrocephalus into existing general HCT programs; and development of specialty centers for longitudinal care of adults with hydrocephalus.

The lack of formal HCT and longitudinal care for young adults with hydrocephalus is a significant health care services problem in the US and Canada that professional societies in neurosurgery and neurology must address. Consensus recommendations of the Hydrocephalus Association Transition Summit address 1) actions by hospitals, health systems, and practices to meet local community needs to improve processes and infrastructure for HCT services and longitudinal care; and 2) actions by professional societies in adult and pediatric neurosurgery and neurology to meet national needs to improve processes and infrastructure for HCT services; to improve training in medical and surgical management of hydrocephalus and in HCT and longitudinal care; and to demonstrate the outcomes and effectiveness of HCT and longitudinal care by promoting research funding.

https://thejns.org/doi/abs/10.3171/2018.6.JNS188
\end{abstract}

KEYWORDS hydrocephalus; health care transition; longitudinal care; Hydrocephalus Association; adolescents; young adults

ABBREVIATIONS AAFP = American Academy of Family Physicians; $A A N=$ American Academy of Neurology; $A A P=$ American Academy of Pediatrics; $A C P=$ American College of Physicians; HCP = health care professional; HCT = health care transition; $\mathrm{PCP}=$ primary care provider; RVU = relative value unit.

SUBMITTED January 2, 2018. ACCEPTED June 27, 2018.

INCLUDE WHEN CITING Published online November 23, 2018; DOI: 10.3171/2018.6.JNS188. 
$\mathrm{P}$ EDIATRIC hydrocephalus is a significant population health issue in the US, with nearly 40,000 annual hospital admissions and associated hospital charges estimated at US\$1.4-2.0 billion in $2008 .{ }^{31}$ The health care needs of this population continue beyond childhood and adolescence; however, pediatric hospitals and pediatric neurosurgeons are often unable to provide care to these patients once they become adults. Each year in the US, an estimated 5000-6000 adolescents and young adults (collectively, youth) with congenital or acquired hydrocephalus (https://wonder.cdc.gov/natality-current.html) ${ }^{23}$ will require transition to the adult health care system, for which many have not been prepared. Regrettably, many of these patients cannot find neurosurgeons willing to care for them as adults. ${ }^{30}$ As a consequence, a significant gap in health care services exists for young adults with hydrocephalus.

The move from the pediatric to the adult health care system is known as health care transition (HCT), a process that has been promoted by the American Academy of Pediatrics (AAP), ${ }^{33}$ the American College of Physicians (ACP), ${ }^{4,5,33}$ the American Academy of Family Physicians (AAFP), ${ }^{4,33}$ and the National Center for Health Care Transition Improvement. ${ }^{15}$ Additionally, the US Department of Health and Human Services "Healthy People 2020" campaign recognizes the need for attention to HCT, and the federal Maternal and Child Health Bureau, along with 37 states, has identified HCT as a health care priority (https:// mchb.tvisdata.hrsa.gov/PrioritiesAndMeasures/NPMDistribution). Within neurosurgery, however, the issue of HCT for youth with hydrocephalus has received limited attention. ${ }^{27,29,30,32}$ Despite the publication nearly a decade ago of a detailed article on the population needs for transitional care for hydrocephalus, little progress has been made. ${ }^{30}$

The Hydrocephalus Association, the largest patient advocacy organization in the US for patients with hydrocephalus and their families, has consistently heard the concerns of its constituency regarding the challenges of HCT. To address these issues, the Hydrocephalus Association convened a Transition Summit in Seattle, Washington, February 17-18, 2017, to raise a call to action by key stakeholders regarding the need for HCT and longitudinal care for patients with hydrocephalus by establishing a set of actions and measurable goals that can be reached within 5-10 years to foster effective HCT for all youth with hydrocephalus throughout the US and Canada.

\section{Summit Organization}

Invited participants included adult and pediatric neurosurgeons and neurologists; neuropsychologists; neuroscientists; pediatricians; family physicians; internists; physiatrists; advanced practice nurses; social workers; Centers for Medicare \& Medicaid Services, state health, and health system administrators; patients with hydrocephalus; and parents of patients with hydrocephalus (Supplemental File 1). Seven plenary sessions consisted of formal presentations by invited speakers (Supplemental File 2). Four breakout groups identified key priorities and recommended actions regarding HCT models and practices, preparing and engaging patients, educating health care professionals, and addressing payment issues. The breakout group results were presented and discussed by all participants to generate consensus recommendations. A writing committee drafted the report, which was circulated to all participants for comment before submission of the manuscript.

The purpose of this report is to present an overview of key issues and consensus recommendations of the summit, rather than to provide a comprehensive review of the literature and research on HCT. This report summarizes the proceedings, beginning with a review of the experiences of patients and families, followed by a review of barriers to HCT and to longitudinal care for youth with hydrocephalus, and then identification of best practices. Consensus recommendations of the summit are presented for actions that should be undertaken to meet local and national needs to improve processes and infrastructure for HCT services for youth and adults with hydrocephalus, as well as to improve national training and research needs.

\section{Experiences of Patients and Families}

To identify topics for the summit, a convenience sample of youth $(n=10)$ and parents $(n=10)$ was recruited to participate in separate focus groups at the Hydrocephalus Association National Conference in Minneapolis, Minnesota, in June 2016. To obtain a broader perspective, members of the same family were not allowed to be in both groups. Public health professionals from the Minnesota Department of Health worked with the groups to explore physician relationships, access to care, feelings around transitioning, and suggestions for improvement. Based on the focus group discussions, as well as the presentations and discussions at the summit involving youth and parents, the following 6 themes regarding HCT were identified.

\section{Inadequately Planned HCT}

Many participants did not have a planned HCT process and felt "left on [their] own to work it out as best [they] can." Some young adults who had not had shunt problems since early in their childhood had not been advised to establish care with adult neurosurgeons, and thus did not realize that they could be at risk for worsening of their condition later in life. ${ }^{11,18,25}$ Patients and parents wished for clearly defined processes to facilitate the transition to the adult health care system.

\section{Difficulty Finding Adult Neurosurgeons}

Many patients reported difficulty in finding neurosurgeons to care for them as adults, which left some without local access to care. Some said that neurosurgeons were unwilling to see them. One parent who was given a listing of adult specialists found that none of them would accept her daughter as a patient. Another family described a neurosurgeon in their hospital who "won't even come into our daughter's room...saying, 'She's not my experiment.", Even when patients found a neurosurgeon, they often were told that no regular follow-up was needed unless something bad happened, and then they should go to the emergency department. 


\section{Inadequate Communication Among Health Care Professionals}

Patients and families said that the adult health care professionals (HCPs) often received inadequate information from the pediatric HCPs and that little communication between them occurred, with the result that the adult HCPs did not always understand the patient's condition and health care needs.

\section{Anxiety}

Patients and families described that their experiences of multiple surgical procedures, complications, and hospitalizations through childhood made them deeply anxious about leaving their pediatric neurosurgeon. In the words of one parent, "You don't go through these experiences without developing this intense fear." Patients reported feeling isolated and alone, and one stated, "I have no one who truly understands how I feel."

\section{Adjusting to the Adult Health Care System}

Youth and families reported that they received little guidance on what to expect or how to manage appointments, medications, and self-care. They noted that adaptation to the culture of adult health care, in which patients are expected to manage and coordinate their own care, can be difficult, especially for young adults with developmental disabilities, who may require more support and guidance than practices usually provide for adult patients. Others noted the challenge that specialist care in adult medicine is done in separate visits, in contrast to the coordinated interdisciplinary care teams that are common in pediatric practice.

\section{Health Insurance}

Finding and maintaining adequate health insurance was described as challenging. Some found that access to adult specialists was restricted because of their insurance plan, or because the adult specialists did not accept their insurance.

\section{Barriers}

The experiences of youth with hydrocephalus and their families suggest failures in both HCT processes and longitudinal care. Patients strongly desire better preparation for $\mathrm{HCT}$, better coordination of the HCT process, and continuity of care with regular follow-up visits in the adult health care system. The summit found that barriers to achieving effective HCT occur at 3 levels: patient and family, health care professionals (both pediatric and adult), and the health care system. Limited research on HCT in hydrocephalus was also considered to be a barrier to HCT.

\section{Patient and Family Psychosocial Barriers}

Many psychological and social factors make HCT difficult. Recent social trends have extended the pre-adult period into "emerging adulthood," spanning ages 18-29 years, which is significantly later than the traditional ages of majority (18-21 years). ${ }^{6}$ Among youth, peer pressure can foster high-risk activities, and discourage self-management and participation in health care. Parents who hover or are overprotective can inhibit a young adult's opportunities to explore and develop independence in managing their own health care. ${ }^{7}$ Poor family cohesion or a disadvantaged environment can undermine the development of independent self-management and impair appropriate utilization of pediatric and adult care. Patients or parents may be unable to take time off work for their appointments, or they may have to rely on public transit or mobility/disability transit, or the distance to specialty centers may be too great.

\section{Barriers in Training and Availability of Key HCPs}

All adult patients with hydrocephalus need a neurosurgeon; however, most adult neurosurgical practices are not designed to provide the longitudinal care and range of services that many of these patients need (see below). Thus, the adequate training, availability, and willingness of adult neurosurgeons to care for these patients is necessary, but not sufficient, to meet their longitudinal care needs. Other specialists, such as neurologists or physiatrists, could help meet these needs, as they have the expertise and practice models to care for patients with chronic neurological conditions. Primary care providers should also play a role in health maintenance, surveillance, and care coordination. Other HCPs, such as nurses, advanced practice nurses, physician assistants, and social workers, may also provide support, but few of these other HCPs have been trained to provide care for patients with hydrocephalus. The issues associated with 5 key specialties are considered here.

\section{Pediatric Neurosurgery}

Pediatric neurosurgeons are well trained in the care of children with hydrocephalus, but few are formally involved in HCT. They and their practices should work with other pediatric HCPs to prepare youth and their parents for the eventual transfer to the adult health care system. ${ }^{20}$

\section{Adult Neurosurgery}

To meet the needs of all youth with hydrocephalus who enter the adult health care system, adult neurosurgeons must be able and willing to participate in their care; however, the consensus at the summit was that many adult neurosurgeons will not accept these patients into their practices. The reasons for this perceived lack of access to adult neurosurgeons are unclear. The International Society for Pediatric Neurosurgery website describes that many adult neurosurgeons have a "self-professed incompetence" to manage adults with complex hydrocephalus. ${ }^{18}$ Yet, shunt surgery and the care of patients with hydrocephalus is a core competency in neurosurgery. ${ }^{1}$ It seems implausible to suggest that adult neurosurgeons lack the ability to care for most patients with hydrocephalus; however, enhanced curricular requirements for the aspects of treatment other than shunt surgery are needed.

Neurosurgeon unwillingness to provide care may play a role in some cases. ${ }^{18}$ At the summit, physicians, nurses, patients, and parents described behaviors among trainees, faculty, and practicing neurosurgeons that suggest a culture exists that adversely affects patients with hydrocephalus. These patients (or their families) may be referred to in 
disparaging terms, or their concerns may be dismissed. These observations suggest the influence of the "hidden curriculum" on the care of patients with hydrocephalus. The hidden curriculum, long recognized as a challenge in medical education, is the tacit teaching and learning of implicit, unstated values, attitudes, practices, and conduct that are contrary to the formal curriculum. ${ }^{19}$

\section{Neurology}

The Child Neurology Foundation and the American Academy of Neurology (AAN) have recently highlighted the role of child neurologists in "planning and coordinating the successful transition of youth with neurologic conditions from the pediatric to adult health care system."10 An unstated implication of this policy is that adult neurologists should also be involved in HCT. Neurologists have the potential to play an important role in the care of children and adults with hydrocephalus, as their skills in differential diagnosis allow them to determine whether signs and symptoms are related to hydrocephalus or to other potential causes ${ }^{35}$ However, neurology residents receive scant formal education in the pathophysiology, diagnosis, and treatment of hydrocephalus, and hydrocephalus is not mentioned in the core competencies for neurology or child neurology. ${ }^{2,4}$ Continuing medical education courses on hydrocephalus at the AAN or the Canadian Neurological Sciences Federation are infrequent.

\section{Physical Medicine and Rehabilitation}

Physiatrists have a role in the care of patients who require longitudinal management for mobility; spasticity; orthoses; assistive technology; and physical, occupational, or speech pathology therapy, particularly for patients with hydrocephalus who also have cerebral palsy or spina bifida. Thus, they may not necessarily require additional training in hydrocephalus; however, they can make significant contributions to the longitudinal care of these patients.

\section{Primary Care}

Primary care providers (PCPs) are essential and should play an important part in the health maintenance and surveillance of adults with hydrocephalus. PCPs play an especially central role in care coordination if they practice in patient-centered medical homes. ${ }^{33}$ In areas with limited access to neurosurgical care, PCPs provide the initial response to patients' concerns about their hydrocephalus. PCPs are often uncomfortable caring for patients with complex conditions,${ }^{24}$ including hydrocephalus, according to summit participants.

\section{Health Care System Barriers}

Health care system barriers to HCT include infrastructure and care models, compensation for health care services, and having adequate health insurance.

\section{Infrastructure and Care Models}

For hydrocephalus, the existing approaches of either unplanned transition or ad hoc transition planning, with or without transfer to adult neurosurgery, are inadequate.
Two prevailing models of planned transition currently exist. One is for patients to remain with their pediatric neurosurgeon after they become adults, but the model works only where pediatric neurosurgeons have privileges in adult hospitals, or where pediatric hospitals allow the admission of adult patients, such as those hospitals that offer lifetime specialty care clinics. Given the demands for pediatric neurosurgeons to care for children, ${ }^{18}$ the summit concluded that this model is not a solution for HCT and longitudinal care on a large scale. The second is for patients who have gone through HCT to be seen in programs that specifically provide longitudinal care for adults with hydrocephalus. Based on discussion at the summit, no more than 5-10 of these programs exist in the US and Canada. The summit concluded that limited availability of such programs is a barrier that can be addressed.

\section{Compensation for Health Care Services}

Summit participants expressed opinions that the relative value unit (RVU) system results in undercompensation for surgical and nonsurgical care of children and adults with hydrocephalus and for transitional care services. Indeed, the RVU-based system is known to value procedures more than evaluation and management services, which has been cited as a disincentive for caring for patients with complex chronic conditions. ${ }^{13}$

\section{Health Insurance}

Currently, the Affordable Care Act guarantees access to insurance for persons with preexisting conditions, allows young adults to stay on a parent's employer-based insurance plan until age 26 years, prohibits annual or lifetime limits on benefits, and limits out-of-pocket spending. Loss of these provisions, which could occur in the context of further health care reform, would be detrimental to young adults with conditions arising in childhood.

Children who have Medicaid, or coverage through the Children's Health Insurance Program (CHIP), may lose coverage at the age of 19 years. ${ }^{3}$ In states that did not expand Medicaid to low-income adults, eligibility for Medicaid requires adults to qualify for Social Security Insurance (SSI). About one-third of young adults lose Medicaid coverage because they fail to meet the qualifications for SSI for adults, which are more stringent than those for children. ${ }^{17}$

Some patients are unable to secure any health insurance at all, because either it is too expensive or the process of finding insurance is too complex for them to navigate. Even for patients with insurance, specialists are not always in network, and many adult HCPs do not accept Medicaid. Evidence exists that declining Medicare reimbursement causes neurosurgeons to restrict the types of patients they treat. $^{28}$

\section{Research}

Published research on the epidemiology, health services, health care expenditures, outcomes, and quality of care for HCT for youth with hydrocephalus is difficult to find. ${ }^{27,29,30,32}$ Paradoxically, the lack of this research may be used as a reason to argue against the need for HCT 
and longitudinal care services for this population. The summit's recommendations call for funding of research on these topics, which will be necessary to assess the outcomes of different models of care.

\section{Best Practices Definition of HCT}

Health care transition has been defined as "the purposeful, planned movement of adolescents and young adults from child-centered to adult-oriented health care systems." 9 The goals of HCT are to enable youth and young adults to use health care services effectively and manage their own health to the extent they are able. HCT involves a set of processes that can be implemented in a variety of settings or infrastructure, ranging from individual HCPs or practices, to formally structured and supported HCT clinics or programs. HCT involves the pediatric health care team, the patient and parents, and adult health care professionals.

Although HCT is often thought of as the handoff of patients from pediatric to adult HCPs, the handoff is one of the last of a series of HCT processes that comprise 3 stages: 1) transition preparation, starting at approximately age 12 years; 2) transfer of care from pediatric to adult health care professionals at ages 18-26 years, depending on local policies; and 3) integration into adult care.

\section{Processes for HCT}

The National Center for Health Care Transition Improvement, Got Transition, has developed best practices based on the AAP/AAFP/ACP Clinical Report ${ }^{33}$ in the form of the "Six Core Elements of Health Care Transition 2.0," ${ }^{15}$ detailed in Table 1. The Six Core Elements approach and tools can be used both by pediatric HCPs who are preparing youth for the transition to adult health care, and by adult HCPs who are integrating youth into their practices. Practices of any size, and in any setting, can improve the experiences and outcomes of transition through use of the Six Core Elements approach, which can be customized based on available local resources.

The summit recommends these processes be used for all youth with hydrocephalus. Tools, templates, and resource inventories tailored to hydrocephalus could support implementation of HCT. ${ }^{5,34,36}$

\section{Settings and Infrastructure for HCT}

Structured interventions in HCT (e.g., special HCT clinics/programs, care coordinators), generally recommended for medically complex patients, have been shown to improve population health, reduce transition barriers, improve adherence to care, and improve service utilization,$^{14}$ consistent with the triple aim in health care ${ }^{26} \mathrm{HCT}$ clinics or programs already exist at some children's hospitals and health systems. Some programs are for a single condition (e.g., spina bifida), and others may include all youth with complex health conditions, regardless of diagnosis. Although these programs may not focus on hydrocephalus, they could improve HCT for youth with hydrocephalus if neurosurgeons become involved. In instances in which a nurse ${ }^{8}$ or a PCP leads the HCT program, education and help from neurosurgeons is needed to design best practices for patients with hydrocephalus. Ultimately, the success of HCT programs depends on the availability of adult HCPs and practices to provide longitudinal care through adulthood, which is the final phase of HCT, integration into adult care.

\section{Models of Longitudinal Care for Hydrocephalus Children}

While pediatric neurosurgeons have traditionally seen children at regular intervals for follow-up, no formal description of longitudinal care for children with hydrocephalus exists, and none is in the 2014 Pediatric Hydrocephalus Guidelines. ${ }^{12}$ Longitudinal care for patients with complex disorders is often performed in multidisciplinary clinics. The dissolution of a spina bifida clinic in 1988 resulted in approximately half of patients failing to have regular care despite the continuing presence of specialists at the same site..$^{21}$

\section{Adults}

Adults with hydrocephalus often do not see neurosurgeons except for emergencies; however, summit participants agreed that longitudinal care with planned, periodic visits is preferred. A 2015 study of 40-year outcomes of patients in Norway who underwent shunt treatment between 1967 and 1970 demonstrates that the risk of complications persists through patients' lifetimes. ${ }^{23}$ The goal of longitudinal care, according to physicians at the summit who run adult programs, is preventive care through periodic, scheduled evaluations for surveillance of issues that are possibly due to the hydrocephalus or related neurological disorders, or to the complications of the treatment of the hydrocephalus. ${ }^{16}$ Surveillance includes 1 ) new or changing symptoms, 2) changes in the neurological examination, or 3) changes in brain imaging findings. A key aspect of the longitudinal care model is that HCPs are responsible for surveillance, which contrasts with the emergency model, in which the patient and family are responsible for surveillance, which carries the risk that they may not recognize important changes, or they may go to the emergency department for issues that could be addressed in the office.

Neurosurgeons cannot and should not be the only physicians participating in longitudinal care of adults with hydrocephalus..$^{20}$ The care of these patients involves more than the shunt, endoscopic third ventriculostomy, or hydrocephalus issues that are managed by neurosurgeons. Most patient concerns, after evaluation, are found not to be due to hydrocephalus, and surgery is not needed. Depending on the patient's comorbid conditions, other specialists, as described above, may be needed to manage epilepsy, headaches, sleep disorders, or psychological and behavioral issues; to monitor and treat bowel and bladder continence; to care for mobility and other activities of daily living, spasticity, wheelchairs, and assistive devices; for educational and vocational issues; or for other problems. PCPs should be involved for standard health maintenance in the context of a primary care medical home.

\section{Infrastructure for Adult Longitudinal Care}

Few clinics or programs specializing in adult hydro- 


\section{TABLE 1. The Six Core Elements for Pediatric and Adult Health Care Professionals}

Transitioning Youth to Adult Health Care Providers: Pediatric HCPs
1) Transition Policy
Each practice/HCP, with input from patients and families, should
develop a transition policy that describes their approach to transition.
Practices should post this policy and share it with youth and families,
beginning at age 12-14 years.
2) Transition Tracking and Monitoring
Criteria and processes should be established to identify transition-
ing youth within a practice, track their progress, and systematically
incorporate relevant steps (e.g., readiness assessment, discussion of
legal issues) into clinical encounters.
3) Transition Readiness
Regular transition readiness assessments should begin at age 14
years to evaluate youths' abilities to manage their own health care
(e.g., knowledge of their condition, tracking health issues, managing
medications, keeping appointments). The assessment doubles as an
intervention, identifying skills that need to be practiced between visits.
4) Transition Planning
In the teenage years, youth should be educated regarding the man-
agement of their health, including information regarding their condi-
tion and medical/surgical history, important issues for daily self-care,
and how to recognize and respond to an emergency. The youth and
family should be educated about the adult approach to care, including
self-advocacy, and decision-making support for youth with intellectual
disabilities. The influence of the law on changes in decision-making,
privacy, and consent that occur when the patient reaches the age of
majority should be discussed. An adult HCP should be identified, as
should other resources, e.g., insurance, durable medical equipment.
A plan of care should summarize key information that will serve to
educate the patient and convey information to a new HCP.
to Thanser of Care

5) Transfer of Care

Transfer of care is the handoff from the pediatric HCP that occurs with the first appointment with the adult HCP. Prior to the appointment, the pediatric HCP should convey key information in a transfer package to the adult HCP, including a carefully crafted medical summary and the latest emergency care plan. Information on guardianship/power of attorney should be included for patients who are not expected to have legal competence or medical decision-making capacity once they reach the age of majority. The final transition readiness assessment and the plan of care with transition goals and pending actions should be included.
6) Transfer Completion
Following the transfer of care to the adult HCP, the pediatric HCP should communicate with the patient and family to confirm the trans- fer of responsibilities and seek feedback, and should offer consulta- tion to the adult HCP as needed.

Integrating Young Adults Into Adult Health Care: Adult HCPs

1) Young Adult Transition and Care Policy

Each practice/HCP, with input from patients and families, should develop a policy that describes their approach to accepting and partnering with new young adult patients. Practices should post this policy and share it with young adults.

2) Young Adult Tracking and Monitoring Criteria and processes should be established to identify transitioning young adults within a practice until age 26 years, track their progress, and systematically incorporate relevant steps (e.g., updating emergency plan, seeking feedback on experience of adult care) into clinical encounters.

3) Transition Readiness/Orientation to Adult Practice A process should be established to welcome and orient young adults into the practice. Youth-friendly online or written information should be provided and a "get-acquainted" appointment offered, if feasible.

4) Transition Planning/Integration Into Adult Practice

The practice should ensure that a complete transfer package is received prior to the first appointment and arrange for consultation assistance from the pediatric HCP, if needed. A pre-visit appointment reminder call should be made, and linkages to insurance resources, self-care information, and community supports provided.

5) Transfer of Care/Initial Visit

The HCP should make special efforts at the initial visits to help the patients become involved in the adult health care system, such as discussing the patient's transfer concerns, privacy and confidentiality issues, and communication preferences. A self-care assessment should be conducted, if not recently completed, and the young adult's health priorities and needs should be discussed. The medical summary and emergency care plan should be updated and shared in portable form with the patient.

6) Transfer Completion/Ongoing Care

The HCP should communicate with the pediatric HCP to confirm transfer and consult as needed; assist the patient to connect with adult specialists and other support services as need; and seek feedback from the patient to assess experience with adult heath care.

Six Core Elements that describe a process to prepare patients for transition, facilitate their transition, and integrate patients into adult-centered care. Adapted from Six Core Elements of Health Care Transition 2.0 (https://www.gottransition.org/resourceGet.cfm?id=206).

cephalus, including young adults, exist. Notable examples are at the University of Washington and Johns Hopkins University, which have neurosurgeons and neurologists providing care, and the University of British Columbia and the University of Calgary, where care is predominantly by neurosurgeons. These centers provide care for simple or complex cases and serve as a home base for patients and families for their hydrocephalus-related issues. ${ }^{16}$ Similar clinics could be created throughout the US and Canada, especially at academic medical centers or tertiary health care systems.

In locations where the creation of specialized clinics for adults with hydrocephalus may not be possible due to geographic or resource constraints, neurosurgeons still have a fiduciary responsibility to care for adults with hydrocephalus who are in the community that their practice serves. 
TABLE 2. Consensus recommendations of the Hydrocephalus Association Transition Summit

1) Local needs: hospitals, health systems, and practices

a) To improve processes and infrastructure for health care transition services and longitudinal care for youth and adults with hydrocephalus:

i) Incorporate the Six Core Elements of Health Care Transition into their existing care processes.

ii) Provide appropriate resources to assist youth and their families through the HCT process.

iii) Develop programs for HCT and longitudinal care for young adults with hydrocephalus, or if geographic and resource constraints prevent the development of such programs, develop relationships with other HCT and longitudinal care programs so that patients can receive appropriate care.

iv) Ensure that all adults with hydrocephalus have access to a primary care medical home that has ready access to appropriate specialists to guide care management.

2) National needs: professional societies in adult and pediatric neurosurgery and neurology

a) To improve processes and infrastructure for health care transition services and longitudinal care for youth and adults with hydrocephalus:

i) Support the development of clinical practice guidelines for hydrocephalus at all stages of life.

ii) Promote the development of programs for health care transition and longitudinal care for youth with hydrocephalus throughout the United States and Canada, or, where this is not feasible, support the incorporation of youth with hydrocephalus into existing health care transition programs.

iii) Incorporate the Six Core Elements of Health Care Transition into clinical practice guidelines for patients with hydrocephalus, and encourage their adoption by pediatric and adult HCPs who provide care for patients with hydrocephalus.

iv) Develop an HCT readiness assessment, medical summary/transfer record, and self-care assessment for youth with hydrocephalus.

b) To meet training needs to improve the knowledge of hydrocephalus among graduating medical students, and to improve the knowledge, skills, attitudes, and competencies of neurosurgeons and neurologists to provide care for patients with hydrocephalus and to participate in HCT:

i) Create learning objectives for pediatric and adult hydrocephalus within undergraduate medical education, and work with the AAMC to incorporate these objectives into the medical school curriculum nationally.

ii) Develop curricular requirements for residency training via the ACGME for the physiology, pathophysiology, and treatment of hydrocephalus, and for health care transition, and include these topics in self-assessment examinations.

iii) Include the topic of health care transition in board certification examinations.

iv) Address the "hidden curriculum" that can create a culture within training and practice that adversely affects patients with hydrocephalus.

v) Provide CME opportunities for hydrocephalus and health care transition. Work with primary care professional societies (e.g., AAP, AAFP, ACP) to create educational products that will help primary care providers to participate in the care of youth and adults with hydrocephalus.

c) To demonstrate the outcomes and effectiveness of HCT and longitudinal care for youth and adults with hydrocephalus:

i) Promote the funding of research in population health, health services, and health care economics of HCT and longitudinal care for youth with hydrocephalus, with the goal of providing data and economic models that can be used to assess the outcomes of different models of care.

AAFP $=$ American Academy of Family Physicians; AAMC $=$ Association of American Medical Colleges; AAP $=$ American Academy of Pediatrics; ACGME $=$ Accreditation Council for Graduate Medical Education; ACP = American College of Physicians; $\mathrm{CME}=$ continuing medical education; $\mathrm{HCT}=$ health care transition.

Neurosurgeons should see these patients periodically, regardless of complexity, because they are responsible for the initial care if the patients require urgent treatment. Patients whose care needs are too complex to be provided only by local physicians and resources can be transferred after stabilization or referred to specialized care centers for outpatient consultation or comanagement when appropriate. Communication between patients' primary neurosurgeons and the centers with specialized care is essential to longitudinal care coordination.

\section{Conclusions and Consensus Recommendations}

In the US and Canada, the number of practices and HCPs using established HCT processes for youth with hydrocephalus, and the number providing longitudinal care for adults with hydrocephalus, are insufficient to meet the population health needs. Despite the existence of national standards for HCT, youth and their families frequently are not helped to prepare for the transition to the adult health care system, and many of them lack access to adult HCPs with expertise in hydrocephalus to provide longitudinal care after they leave the pediatric health care system.
To address the gap between the population health needs and the health services for HCT and longitudinal care, the participants of the Hydrocephalus Association Transition Summit recommend that adult and pediatric neurosurgeons, and adult and pediatric neurologists, and their respective professional societies enact the consensus recommendations in Table 2, which are summarized here: 1) To meet the local needs of their communities, hospitals, health systems, and practices should undertake actions to improve processes and infrastructure for HCT services and longitudinal care. 2) To meet national needs, professional societies in adult and pediatric neurosurgery and neurology should undertake actions a) to improve processes and infrastructure for HCT services; b) to improve training in medical and surgical management of hydrocephalus and in HCT and longitudinal care; and c) to demonstrate the outcomes and effectiveness of HCT and longitudinal care by promoting research funding.

Further recommendations of the Hydrocephalus Association Transition Summit, covering the topics of payment, insurance, support and education of families, advocacy, and the roles of other professions, including nursing and social work, are available at the Hydrocephalus Association website (www.hydroassoc.org/transition). 


\section{Acknowledgments}

The Hydrocephalus Association Transition Summit participants recognize that the issues in HCT and longitudinal care described in this report are not unique to youth with hydrocephalus, and that many youth with other chronic neurologic disorders, and their families, face similar concerns. ${ }^{23} \mathrm{We}$ encourage the development and adoption of the best practices for HCT for all patient populations with similar needs.

We wish to acknowledge Sarah MapelLentz, JD, MPH, and Michelle Gin, MPH, for their valuable contribution in conducting the focus groups of youth and families regarding their concerns on HCT. We wish to acknowledge the leadership and staff of the Hydrocephalus Association for their extraordinary efforts in organizing the Transition Summit. We wish to express our sincere gratitude to all participants of the Hydrocephalus Association Transition Summit for their efforts during the summit to identify key issues and propose recommendations that are reflected in this report. We wish to acknowledge the contribution of Carol Berkower, PhD, for her work for hire to attend the Hydrocephalus Association Transition Summit to take notes and submit a draft report that was then modified to create this paper.

\section{References}

1. Accreditation Council for Graduate Medical Education: Program Requirements for Graduate Medical Education in Neurological Surgery. (https://www.acgme.org/Portals/0/ PFAssets/ProgramRequirements/160_NeurologicalSurgery_2017-07-01.pdf?ver=2017-06-30-085318-930) [Accessed August 14, 2018]

2. Accreditation Council for Graduate Medical Education: Program Requirements for Graduate Medical Education in Neurology. (https://www.acgme.org/Portals/0/PFAssets/ ProgramRequirements/180_neurology_2017-07-01.pdf) [Accessed August 14, 2018]

3. Altman S, O'Connor S, Anapolsky E, Sexton L: Federal and state benefits for transition age youth. J Pediatr Rehabil Med 7:71-77, 2014

4. American Board of Psychiatry \& Neurology: Child and Adolescent Psychiatry Core Competencies Outline. ABPN.com. (https://www.abpn.com/wp-content/uploads/2015/02/2011 core_CAP_MREE.pdf) [Accessed August 14, 2018]

5. American College of Physicians: ACP Pediatric to Adult Care Transitions Initiative. ACPOnline.org. (https:// www.acponline.org/clinical-information/high-value-care/ resources-for-clinicians/pediatric-to-adult-care-transitionsinitiative/about) [Accessed August 14, 2018]

6. Arnett JJ: Emerging adulthood. A theory of development from the late teens through the twenties. Am Psychol 55:469-480, 2000

7. Berry JG, Kusminsky M, Foley SM, Hobbs N, Queally JT, Bauer SB, et al: Strategic directions for transition to adulthood for patients with spina bifida. J Pediatr Neurol 11:211220, 2013

8. Betz CL, Smith KA, Van Speybroeck A, Hernandez FV, Jacobs RA: Movin' On Up: an innovative nurse-led interdisciplinary health care transition program. J Pediatr Health Care 30:323-338, 2016

9. Blum RW, Garell D, Hodgman CH, Jorissen TW, Okinow NA, Orr DP, et al: Transition from child-centered to adult health-care systems for adolescents with chronic conditions. A position paper of the Society for Adolescent Medicine. J Adolesc Health 14:570-576, 1993

10. Brown LW, Camfield P, Capers M, Cascino G, Ciccarelli M, de Gusmao CM, et al: The neurologist's role in supporting transition to adult health care: a consensus statement. Neurology 87:835-840, 2016
11. Cowan JA, McGirt MJ, Woodworth G, Rigamonti D, Williams MA: The syndrome of hydrocephalus in young and middle-aged adults (SHYMA). Neurol Res 27:540-547, 2005

12. Flannery AM, Mitchell L: Pediatric hydrocephalus: systematic literature review and evidence-based guidelines. Part 1: Introduction and methodology. J Neurosurg Pediatr 14 (1 Suppl 1):3-7, 2014

13. Frist W, Schroeder S, Bigby JA, Brennan TA, Delbanco S, Gallagher T, et al: Report of the National Commission in Physician Payment Reform. Washington, DC: Robert Wood Johnson Foundation, 2013 (https://www.rwjf.org/content/ dam/farm/reports/issue_briefs/2013/rwjf404629) [Accessed August 14, 2018]

14. Gabriel P, McManus M, Rogers K, White P: Outcome evidence for structured pediatric to adult health care transition interventions: a systematic review. J Pediatr 188:263-269, 269.e1-269.e15, 2017

15. Got Transition: Six Core Elements of Health Care Transition 2.0. Transitioning Youth to an Adult Health Care Provider. Washington, DC: National Alliance to Advance Adolescent Health, 2014 (http://www.gottransition.org/ resourceGet.cfm?id=208) [Accessed August 14, 2018]

16. Hamilton MG: Treatment of hydrocephalus in adults. Semin Pediatr Neurol 16:34-41, 2009

17. Hemmeter J, Gilby E: The age-18 redetermination and postredetermination participation in SSI. Soc Secur Bull 69:1-25, 2009

18. International Society for Pediatric Neurosurgery: Transition of care for long-term management of hydrocephalus in children. ISPN Guide to Pediatric Neurosurgery. (https:// www.ispn.guide/hydrocephalus-and-other-anomalies-of-csfcirculation-in-children/long-term-management-and-outcomeof-hydrocephalus-in-children-homepage/long-term-management-of-hydrocephalus-in-children/transition-of-carefor-long-term-management-of-hydrocephalus-in-children/) [Accessed August 14, 2018]

19. Inui TS: A Flag in the Wind: Educating for Professionalism in Medicine. Washington, DC: Association of American Medical Colleges, 2003

20. James HE, MacGregor TL, Childers DO Jr, La Corte E, Aldana PR: Pediatric neurosurgery patients need more than a neurological surgeon: a clinical experience. Pediatr Neurosurg 49:63-68, 2013

21. Kaufman BA, Terbrock A, Winters N, Ito J, Klosterman A, Park TS: Disbanding a multidisciplinary clinic: effects on the health care of myelomeningocele patients. Pediatr Neurosurg 21:36-44, 1994

22. McManus MA, Pollack LR, Cooley WC, McAllister JW, Lotstein D, Strickland B, et al: Current status of transition preparation among youth with special needs in the United States. Pediatrics 131:1090-1097, 2013

23. Munch TN, Rostgaard K, Rasmussen MLH, Wohlfahrt J, Juhler M, Melbye M: Familial aggregation of congenital hydrocephalus in a nationwide cohort. Brain 135:2409-2415, 2012

24. Okumura MJ, Heisler M, Davis MM, Cabana MD, Demonner $\mathrm{S}$, Kerr EA: Comfort of general internists and general pediatricians in providing care for young adults with chronic illnesses of childhood. J Gen Intern Med 23:1621-1627, 2008

25. Paulsen AH, Lundar T, Lindegaard KF: Pediatric hydrocephalus: 40-year outcomes in 128 hydrocephalic patients treated with shunts during childhood. Assessment of surgical outcome, work participation, and health-related quality of life. J Neurosurg Pediatr 16:633-641, 2015

26. Prior M, McManus M, White P, Davidson L: Measuring the "triple aim" in transition care: a systematic review. Pediatrics 134:e1648-e1661, 2014

27. Rekate HL: The pediatric neurosurgical patient: the challenge of growing up. Semin Pediatr Neurol 16:2-8, 2009 
28. Rosenow JM, Orrico KO: Neurosurgeons' responses to changing Medicare reimbursement. Neurosurg Focus 37(5):E12, 2014

29. Rothstein DH, Li V: Transitional care in pediatric neurosurgical patients. Semin Pediatr Surg 24:79-82, 2015

30. Simon TD, Lamb S, Murphy NA, Hom B, Walker ML, Clark EB: Who will care for me next? Transitioning to adulthood with hydrocephalus. Pediatrics 124:1431-1437, 2009

31. Simon TD, Riva-Cambrin J, Srivastava R, Bratton SL, Dean JM, Kestle JR: Hospital care for children with hydrocephalus in the United States: utilization, charges, comorbidities, and deaths. J Neurosurg Pediatr 1:131-137, 2008

32. Vinchon M, Dhellemmes P: [Follow-up of adult patients treated during childhood for hydrocephalus.] Neurochirurgie 54:587-596, 2008 (Fr)

33. White PH, Cooley WC: Supporting the health care transition from adolescence to adulthood in the medical home. Pediatrics 142:e20182587, 2018

34. Wiemann CM, Hergenroeder AC, Bartley KA, SanchezFournier B, Hilliard ME, Warren LJ, et al: Integrating an EMR-based transition planning tool for CYSHCN at a children's hospital: a quality improvement project to increase provider use and satisfaction. J Pediatr Nurs 30:776-787, 2015

35. Williams MA, Malm J: Diagnosis and treatment of idiopathic normal pressure hydrocephalus. Continuum (Minneap Minn) 22 (2 Dementia):579-599, 2016

36. Wood DL, Sawicki GS, Miller MD, Smotherman C, LukensBull K, Livingood WC, et al: The Transition Readiness Assessment Questionnaire (TRAQ): its factor structure, reliability, and validity. Acad Pediatr 14:415-422, 2014

\section{Disclosures}

This work was supported by a generous gift from the Theodore W. Batterman Family Foundation.

\section{Author Contributions}

Conception and design: all authors. Acquisition of data: Williams, van der Willigen, Hamilton. Analysis and interpretation of data: all authors. Drafting the article: all authors. Critically revising the article: all authors. Reviewed submitted version of manuscript: all authors. Approved the final version of the manuscript on behalf of all authors: Williams. Study supervision: Williams, van der Willigen.

\section{Supplemental Information \\ Online-Only Content}

Supplemental material is available with the online version of the article.

Supplemental File 1. https://thejns.org/doi/suppl/10.3171/2018. 6.JNS188.

Supplemental File 2. https://thejns.org/doi/suppl/10.3171/2018. 6.JNS188.

\section{Correspondence}

Michael A. Williams: University of Washington, Seattle, WA. maw99@uw.edu. 